\title{
Association analysis of colorectal cancer susceptibility variants with gastric cancer in a Chinese Han population
}

\author{
C.-P. Zhou', H.-Z. Pan'2, F.-X Li', N.-Y. Hu ${ }^{3}$, M. $\mathrm{Li}^{4}$ and X.-X. Yang ${ }^{4}$ \\ ${ }^{1}$ The First Clinical College, Southern Medical University, Guangzhou, China \\ ${ }^{2}$ Clinical Laboratory of Affiliated Hospital, \\ Medical College and Clinical Medicine Postdoctoral Mobile Research Station, \\ Qingdao University, Qingdao, China \\ ${ }^{3}$ Department of Clinical, First Affiliated Hospital of Nanchang University, \\ Nanchang, China \\ ${ }^{4}$ School of Biotechnology, Southern Medical University, Guangzhou, China \\ Corresponding author: X.-X. Yang \\ E-mail: yxxzb@sohu.com
}

Genet. Mol. Res. 13 (2): 3673-3680 (2014)

Received July 10, 2013

Accepted December 6, 2013

Published May 9, 2014

DOI http://dx.doi.org/10.4238/2014.May.9.10

ABSTRACT. Evidence suggests that some genetic variants are risk factors
for both colorectal cancer (CRC) and gastric cancer $(\mathrm{GC})$. Thus, we selected
12 reported single nucleotide polymorphisms (SNPs) from genome-wide
association studies of CRC and conducted this case-control study to assess
the associations between these SNPs and the risk for GC in a southern
Chinese population. All SNPs were genotyped in 249 individuals with
$\mathrm{GC}$ and 292 healthy population-matched subjects using the Sequenom
MassArray iPLEX System. Association analyses based on the $\chi^{2}$ test and
binary logistic regression were performed to determine the odds ratio (OR)
and $95 \%$ confidence interval $(95 \% \mathrm{CI})$ for each SNP. A stratified analysis
by gender was also performed. Borderline significant associations were
observed for rs $4444235(\mathrm{P}=0.070)$ and rs $10411210(\mathrm{P}=0.084)$, both fitting
the overdominant model. The rs $4444235 \mathrm{CT}$ genotype showed a protective 
effect $(\mathrm{OR}=0.72,95 \% \mathrm{CI}=0.50-1.03)$, while the rs $10411210 \mathrm{CT}$ genotype was a risk factor $(\mathrm{OR}=1.40,95 \% \mathrm{CI}=0.96-2.05)$ as compared with the CC+TT genotype. In the female subgroup, the rs6983267 GT genotype (compared with TT, OR $=2.31,95 \% \mathrm{CI}=1.07-4.99$ ) and the rs $10505477 \mathrm{CT}$ genotype (compared with TT, OR $=2.36,95 \% \mathrm{CI}=1.09-5.11$ ) significantly increased the risk for GC. No significant association was detected for the other SNPs. These results provide evidence that known genetic variants associated with CRC risk may also confer risk for GC.

Keywords: Single nucleotide polymorphism; Susceptibility; Gastric Cancer; Colorectal cancer;

\section{INTRODUCTION}

Gastric cancer (GC) is a global public health concern, ranking as the fourth leading cause of cancer mortality, with a 5-year survival rate of only $20 \%$ (Crew and Neugut, 2006). Several risk factors have been identified through epidemiological studies for GC, including Helicobacter pylori infection, low fiber intake, and tobacco smoking (Epplein et al., 2008; Ladeiras-Lopes et al., 2008). Environmental exposure and genetic susceptibility are also thought to contribute to GC risk (Tan et al., 2012). The accumulation of specific genetic alterations, including polymorphisms, contributes to gastric tumorigenesis (González et al., 2002).

Single nucleotide polymorphisms (SNPs) have attracted considerable attention in recent years as potential markers for predicting disease susceptibility. Genome-wide association studies (GWAS) of many common genetic variants have examined different individuals to determine whether a variant is associated with a trait. This method has become a major strategy for identifying genetic susceptibility factors for polygenic diseases, including cancers.

Recently, a GWAS performed in a North-Central Chinese population identified 7 SNPs at loci 1q22 and 10q23 as being significantly associated with GC susceptibility (Abnet et al., 2010). However, GWAS have been criticized for consistently displaying a low effect size of SNPs with an apparently extremely significant $P$ value.

Thus, the re-validation of GWAS-derived SNPs in different populations and different diseases has become an important addition to the discovery of new variants. Furthermore, SNP information regarding GC from GWAS is rather limited, particularly compared with colorectal cancer (CRC), another common gastrointestinal cancer.

Evidence suggests that some genetic variants are risk factors for both CRC and GC (Li et al., 2011, 2012). Based on this hypothesis, we traced some well-known colorectal cancer GWAS-identified SNPs with GC susceptibility to assess potential associations. Thus, in this study, 12 "hit" SNPs identified by CRC GWAS analysis were selected and then assessed to determine whether these SNPs are suitable markers for GC.

\section{MATERIAL AND METHODS}

\section{Subjects}

The samples used in this study were obtained from individuals visiting the outpatient 
and inpatient clinics of the First Affiliated Hospital of Nanchang University, Nanchang, Jiangxi Province, China. The ethics committee of Southern Medical University approved this study and all subjects provided written informed consent.

A total of 249 GC patients and 292 healthy subjects were enrolled between 2009 and 2010. All diagnoses of GC were confirmed histologically. Control subjects were cancer-free individuals selected randomly from the hospital's outpatient department. The mean ages of the patients and the control subjects were 54.82 (standard deviation, SD =12.47) and 58.65 (SD $=16.14$ ) years, respectively. Additionally, among the 249 cases, 176 were adenocarcinomas by pathological type, 43 and 79 were cardiac cancers and non-cardiac cancers by tumor site, respectively, and 110 and 15 were lymph node metastases and distant metastases by tumor stage, respectively.

\section{Selection of SNPs from colorectal cancer GWAS}

Based on previous studies, we selected 8 commonly identified SNPs from GWAS: rs12701937, rs16892766, rs7014346, rs6983267, rs10505477, rs10795668, rs719725, and rs3802842 (Zanke et al., 2007; Tomlinson et al., 2007, 2008; Tenesa et al., 2008; Lascorz et al., 2010), and 4 (rs4444235, rs9929218, rs10411210, and rs961253) from meta-analyses based on GWAS data (Houlston et al., 2008) (Table 1).

\section{Table 1. Genotype characteristics of 12 chosen colorectal cancer susceptibility variants.}

\begin{tabular}{|c|c|c|c|c|c|c|}
\hline No. & SNP & Chr. & Location/Nearest gene & Major allele & Minor allele & $\mathrm{P}$ \\
\hline 1 & rs12701937 & $7 \mathrm{p} 14.1$ & Intergenic/GLI3,INHBA & $\mathrm{C}$ & $\mathrm{T}$ & $1.1 \times 10^{-3}$ \\
\hline 2 & rs16892766 & $8 \mathrm{q} 23.3$ & Intergenic/EIF3H & A & - & $3 \times 10^{-18}$ \\
\hline 3 & rs10795668 & $10 \mathrm{p} 14$ & Intergenic/BC031880 & G & A & $3 \times 10^{-13}$ \\
\hline 4 & rs7014346 & $8 \mathrm{q} 24.21$ & Intergenic/POU5FIP1, HsG57825, DQ515897 & G & A & $9 \times 10^{-26}$ \\
\hline 5 & rs6983267 & $8 \mathrm{q} 24.21$ & Intergenic/MYC & $\mathrm{T}$ & $\mathrm{G}$ & $7 \times 10^{-11}$ \\
\hline 6 & rs 10505477 & $8 \mathrm{q} 24.21$ & Intergenic/ORF DQ515897 & $\mathrm{C}$ & $\mathrm{T}$ & $3 \times 10^{-11}$ \\
\hline 7 & rs719725 & 9 p24 & Intergenic & $\mathrm{A}$ & $\mathrm{C}$ & $2.3 \times 10^{-2}$ \\
\hline 8 & rs 3802842 & $11 \mathrm{q} 23$ & Intergenic/C11orf93 & $\mathrm{A}$ & $\mathrm{C}$ & $4 \times 10^{-7}$ \\
\hline 9 & rs 4444235 & $14 \mathrm{q} 22.2$ & Intergenic/BMP4 & $\mathrm{T}$ & $\mathrm{C}$ & $8 \times 10^{-10}$ \\
\hline 10 & rs9929218 & $16 \mathrm{q} 22.1$ & Intron/CDH1 & G & $\mathrm{A}$ & $1 \times 10^{-8}$ \\
\hline 11 & rs 10411210 & $19 \mathrm{q} 13.1$ & Intron/RHPN2 & $\mathrm{C}$ & $\mathrm{T}$ & $5 \times 10^{-9}$ \\
\hline 12 & rs961253 & $20 \mathrm{p} 12.3$ & Intergenic/BMP2 & $\mathrm{C}$ & $\mathrm{A}$ & $2 \times 10^{-10}$ \\
\hline
\end{tabular}

\section{Genotyping}

Peripheral blood samples were drawn from participants at the First Affiliated Hospital of Nanchang University. Samples were delivered frozen by express mail to the School of Biotechnology, Southern Medical University, and stored at $-70^{\circ} \mathrm{C}$. Genomic DNA was extracted using a commercial blood DNA kit (Tiangen Biotech; Beijing, China) according to manufacturer instructions and stored at $-70^{\circ} \mathrm{C}$ until required.

The 12 SNPs were genotyped using MassARRAY genotyping technology (Sequenom, Inc.; San Diego, CA, USA) according to manufacturer instructions. Primers were designed using proprietary software, Assay Design 3.1, provided by Sequenom Inc. The primer sequences are shown in Table $\mathbf{S 1}$. 


\section{Statistical analysis}

Exclusion criteria for SNPs were as follows: 1) $<85 \%$ genotype call rate, 2) minor allele frequency (MAF) $<5 \%$ in cases or controls, and 3) Hardy-Weinberg equilibrium exact $\mathrm{P}$ value $<0.05$ in cases or controls; SNPs satisfying 1 or more of these criteria were excluded.

Genotype and allele frequencies were compared using chi-squared tests. Odds ratios (ORs) and 95\% confidence intervals (CIs) were estimated by a logistic regression analysis and adjusted for age and gender. Statistical analyses were performed using the web-based tool SNPstats (http://bioinfo.iconcologia.net/SNPstats). The results from this calculator were consistent with those obtained using the SPSS software (ver. 13.0; Solé et al., 2006). Gender stratification analysis was preformed after analysis. All statistical analyses were 2-tailed, and the significance level was set at 0.05 .

\section{RESULTS}

Two SNPs (rs719725 and rs3802842) were excluded because their genotype call rates were $<80 \%$; the other SNPs passed the threshold. One SNP (rs16892766) was monomorphic and was excluded. The other 9 SNPs all passed the Hardy-Weinberg equilibrium exact test $(\mathrm{P}>0.05)$ in cases and controls. MAFs in controls were similar to data of Han Chinese in Beijing (CHB) and Japanese in Tokyo (JPT) populations from HapMap (http://hapmap.ncbi.nlm.nih.gov/) (Table 2).

\begin{tabular}{|c|c|c|c|c|c|c|c|}
\hline \multirow[t]{2}{*}{ SNP/Allele } & \multirow[t]{2}{*}{ Minor allele } & \multicolumn{2}{|c|}{ Present study (\%) } & \multicolumn{4}{|c|}{ Hapmap (\%) } \\
\hline & & Control & Case & $\mathrm{CHB}$ & JPT & European & African \\
\hline rs12701937 & $\mathrm{T}$ & 32.5 & 31.9 & 33.3 & 37.8 & 43.2 & 0 \\
\hline rs10795668 & A & 33.7 & 34.8 & 34.4 & 40 & 35.8 & 0.8 \\
\hline rs7014346 & A & 33.6 & 32.1 & 35.6 & 21.1 & 26.7 & 46.7 \\
\hline rs6983267 & G & 44 & 46.1 & 37.2 & 29.1 & 48.7 & 98.2 \\
\hline rs10505477 & $\mathrm{T}$ & 43.4 & 46.3 & 37.8 & 33.3 & 42.2 & 89.2 \\
\hline rs4444235 & $\mathrm{C}$ & 46.8 & 47.9 & 52.3 & 54.7 & 44.2 & 29.5 \\
\hline rs9929218 & $\mathrm{A}$ & 19.2 & 18 & 17.4 & 16.3 & 29.5 & 29.2 \\
\hline rs10411210 & $\mathrm{T}$ & 18 & 20.8 & 18.6 & 13.4 & 8.4 & 45.1 \\
\hline rs961253 & $\mathrm{A}$ & 6.9 & 8.4 & 5.8 & 18 & 40.3 & 32.3 \\
\hline
\end{tabular}

$\mathrm{CHB}=$ Han Chinese in Beijing; JPT $=$ Japanese in Tokyo.

The genetic models for inheritance evaluation were not significant for any SNP, but 2 SNPs (rs4444235 and rs10411210) showed borderline significance $(\mathrm{P}=0.070$ and $\mathrm{P}=0.084$, respectively), both fitting the overdominant model (Table 3 ). These results suggest a possible inverse association between the rs444235 CT genotype $(\mathrm{OR}=0.72,95 \% \mathrm{CI}=0.50-1.03)$ and a possible positive association of the $\mathrm{rs} 10411210 \mathrm{CT}$ genotype $(\mathrm{OR}=1.40,95 \% \mathrm{CI}=0.96-2.05)$ and $\mathrm{GC}$ risk as compared with the $\mathrm{CC}+\mathrm{TT}$ genotypes.

A subsequent gender stratification analysis showed that in the female group, the rs6983267 GT genotype (compared with TT, OR $=2.31,95 \% \mathrm{CI}=1.07-4.99$ ) and the rs $10505477 \mathrm{CT}$ genotype (compared with $\mathrm{TT}, \mathrm{OR}=2.36,95 \% \mathrm{CI}=1.09-5.11$ ) significantly increased GC risk (Table 4). 


\begin{tabular}{|c|c|c|c|c|c|c|}
\hline \multirow[t]{2}{*}{ SNP } & \multirow[t]{2}{*}{ Model } & \multirow[t]{2}{*}{ Genotype } & \multicolumn{2}{|c|}{ Frequency N (\%) } & \multirow{2}{*}{$\frac{\text { Adjusted OR }}{(95 \% \mathrm{CI})}$} & \multirow[t]{2}{*}{$P$} \\
\hline & & & Control & Case & & \\
\hline \multirow[t]{3}{*}{ rs12701937 } & \multirow[t]{3}{*}{ Dominant } & $\mathrm{CC}$ & $124(46.6 \%)$ & $115(48.3 \%)$ & Reference & \multirow{3}{*}{0.97} \\
\hline & & $\mathrm{CT}$ & $111(41.7 \%)$ & $94(39.5 \%)$ & $0.98(0.67-1.43)$ & \\
\hline & & TT & $31(11.7 \%)$ & $29(12.2 \%)$ & $1.06(0.60-1.87)$ & \\
\hline \multirow[t]{3}{*}{ rs10795668 } & \multirow[t]{3}{*}{ Dominant } & GG & $123(46.4 \%)$ & $98(41.9 \%)$ & Reference & \multirow{3}{*}{0.3} \\
\hline & & $\mathrm{AG}$ & $105(39.6 \%)$ & $109(46.6 \%)$ & $1.29(0.88-1.89)$ & \\
\hline & & AA & $37(14 \%)$ & $27(11.5 \%)$ & $0.90(0.51-1.59)$ & \\
\hline \multirow[t]{3}{*}{ rs7014346 } & \multirow[t]{3}{*}{ Dominant } & GG & $119(44.7 \%)$ & $105(44.3 \%)$ & Reference & \multirow{3}{*}{0.28} \\
\hline & & GA & $115(43.2 \%)$ & $112(47.3 \%)$ & $1.13(0.78-1.64)$ & \\
\hline & & $\mathrm{AA}$ & $32(12 \%)$ & $20(8.4 \%)$ & $0.69(0.37-1.28)$ & \\
\hline \multirow[t]{3}{*}{ rs6983267 } & \multirow{3}{*}{ Dominant } & TT & $74(32.6 \%)$ & $70(28.5 \%)$ & Reference & \multirow{3}{*}{0.49} \\
\hline & & GT & $106(46.7 \%)$ & $125(50.8 \%)$ & $1.29(0.84-1.97)$ & \\
\hline & & GG & $47(20.7 \%)$ & $51(20.7 \%)$ & $1.08(0.64-1.82)$ & \\
\hline \multirow[t]{3}{*}{ rs10505477 } & \multirow[t]{3}{*}{ Dominant } & $\mathrm{CC}$ & $75(33 \%)$ & $70(28.9 \%)$ & Reference & \multirow{3}{*}{0.64} \\
\hline & & $\mathrm{CT}$ & $107(47.1 \%)$ & $120(49.6 \%)$ & $1.23(0.80-1.88)$ & \\
\hline & & TT & $45(19.8 \%)$ & $52(21.5 \%)$ & $1.15(0.68-1.95)$ & \\
\hline \multirow[t]{5}{*}{ rs4444235 } & \multirow[t]{3}{*}{ Dominant } & TT & $71(26.7 \%)$ & $68(28.8 \%)$ & Reference & \multirow{3}{*}{0.15} \\
\hline & & $\mathrm{CT}$ & $141(53 \%)$ & $110(46.6 \%)$ & $0.77(0.51-1.18)$ & \\
\hline & & $\mathrm{CC}$ & $54(20.3 \%)$ & $58(24.6 \%)$ & $1.19(0.72-1.97)$ & \\
\hline & \multirow[t]{2}{*}{ Overdominant } & $\mathrm{TT}+\mathrm{CC}$ & $125(47 \%)$ & $126(53.4 \%)$ & Reference & \multirow{3}{*}{0.07} \\
\hline & & $\mathrm{CT}$ & $141(53 \%)$ & $110(46.6 \%)$ & $0.72(0.50-1.03)$ & \\
\hline \multirow[t]{3}{*}{ rs9929218 } & \multirow[t]{3}{*}{ Dominant } & GG & $174(65.2 \%)$ & $156(66.1 \%)$ & Reference & \\
\hline & & GA & $83(31.1 \%)$ & $75(31.8 \%)$ & $1.02(0.70-1.50)$ & \multirow[t]{2}{*}{0.57} \\
\hline & & AA & $10(3.8 \%)$ & $5(2.1 \%)$ & $0.57(0.19-1.72)$ & \\
\hline rs10411210 & Dominant & $\mathrm{CC}$ & $181(68 \%)$ & $146(61.3 \%)$ & Reference & \\
\hline & & $\mathrm{TC}$ & $74(27.8 \%)$ & $85(35.7 \%)$ & $1.38(0.94-2.02)$ & 0.19 \\
\hline & & TT & $11(4.1 \%)$ & $7(2.9 \%)$ & $0.75(0.28-2.00)$ & \\
\hline & Overdominant & $\mathrm{CC}+\mathrm{TT}$ & $192(72.2 \%)$ & $153(64.3 \%)$ & Reference & \\
\hline & & $\mathrm{CT}$ & $74(27.8 \%)$ & $85(35.7 \%)$ & $1.40(0.96-2.05)$ & 0.087 \\
\hline rs961253 & Dominant & $\mathrm{CC}$ & $230(86.5 \%)$ & $200(84 \%)$ & Reference & \\
\hline & & $\mathrm{AC}$ & $35(13.2 \%)$ & $36(15.1 \%)$ & $1.16(0.69-1.93)$ & 0.61 \\
\hline & & AA & $1(0.4 \%)$ & $2(0.8 \%)$ & $2.69(0.24-30.21)$ & \\
\hline
\end{tabular}

Table 4. Genotype distributions of rs6983267 and rs10505477 in male and female subjects respectively.

\begin{tabular}{|c|c|c|c|c|c|c|c|c|}
\hline \multirow[t]{2}{*}{ SNP } & \multirow[t]{2}{*}{ Model } & \multirow[t]{2}{*}{ Genotype } & \multicolumn{3}{|c|}{ Male } & \multicolumn{3}{|c|}{ Female } \\
\hline & & & Control & Case & OR $(95 \% \mathrm{CI})$ & Control & Case & OR $(95 \% \mathrm{CI})$ \\
\hline \multirow[t]{3}{*}{ rs6983267 } & Dominant & $\mathrm{TT}$ & $40(30.3 \%)$ & $57(32.4 \%)$ & Reference & $34(35.8 \%)$ & $13(18.6 \%)$ & Reference \\
\hline & & GT & $61(46.2 \%)$ & $81(46.0 \%)$ & $0.96(0.57-1.63)$ & $45(47.4 \%)$ & $44(62.8 \%)$ & $2.31(1.07-4.99)$ \\
\hline & & GG & $31(23.5 \%)$ & $38(21.6 \%)$ & $0.90(0.48-1.70)$ & $16(16.8 \%)$ & $13(18.6 \%)$ & $1.65(0.61-4.45)$ \\
\hline \multirow[t]{3}{*}{ rs10505477 } & Dominant & $\mathrm{CC}$ & $40(30.3 \%)$ & $57(32.9 \%)$ & Reference & $35(36.8 \%)$ & $13(18.8 \%)$ & Reference \\
\hline & & $\mathrm{CT}$ & $63(47.7 \%)$ & $77(44.5 \%)$ & $0.88(0.52-1.50)$ & $44(46.3 \%)$ & $43(62.3 \%)$ & $2.36(1.09-5.11)$ \\
\hline & & TT & $29(22.0 \%)$ & $39(22.5 \%)$ & $0.98(0.52-1.85)$ & $16(16.8 \%)$ & $13(18.8 \%)$ & $1.70(0.63-4.58)$ \\
\hline
\end{tabular}

\section{DISCUSSION}

In the present study, we evaluated 12 SNPs identified by GWAS of CRC in an independent Chinese population of patients with GC. Among these SNPs, 1 (rs16892766) was monomorphic. Two SNPs (rs719725 and rs3802842) were excluded because they did not pass the threshold set. Two borderline-significant associations were observed between rs4444235 ( $\mathrm{P}=$ $0.070)$ and $\operatorname{rs} 10411210(\mathrm{P}=0.084)$ and $\mathrm{GC}$ in the present population. Furthermore, genderstratified analysis identified 2 SNPs (rs6983267 and rs10505477) that were significantly associated with GC in the female subgroup. No significant association was detected for the other SNPs. 
Because we sought to identify novel GC risk-related variants from CRC GWAS, SNPs were not randomly chosen, but instead obtained from previous studies. Among these SNPs, rs6983267 at region 8q24 is an established risk locus for many common malignant cancers, such as prostate (Beuten et al., 2009), ovarian (White et al., 2010), breast (Fletcher et al., 2008), and gastric cancers (Lochhead et al., 2011; Guo et al., 2011), but not for colon cancer. It has been reported that rs6983267 showed a significant association with GC risk in a Chinese population (Guo et al., 2011). Another SNP at 8q24, rs10505477, which maps to approximately $5.86 \mathrm{~kb}$ centromeric to rs6983267 and has high linkage disequilibrium with rs6983267, was also reported to confer risk for CRC (Zanke et al., 2007) and ovarian cancer (Ghoussaini et al., 2008). This SNP has also been examined in GC, but no significant association has been reported (Lochhead et al., 2011; Guo et al., 2011). The SNPs rs6983267, rs7014346, and rs10505477 are also from the 8q24 region, which is a gene desert, but an established risk-associated locus in CRC and prostate cancer (Takata et al., 2010; Schumacher et al., 2011). Furthermore, 8 q24 has also been reported to be associated with glioma (Shete et al., 2009), breast cancer (Easton et al., 2007; Turnbull et al., 2010; Fletcher et al., 2011), lymphoma, and leukemia (Crowther-Swanepoel et al., 2010; Enciso-Mora et al., 2010), bladder cancer (Kiemeney et al., 2008; Rothman et al., 2010), and ovarian cancer (Goode et al., 2010). The SNP rs 12701937 (7p14.1) was first reported to be associated with CRC in German familial CRC cases. The SNP rs10795668 (10p14) was found to be associated with both CRC (Tomlinson et al., 2008) and a decreased risk of CRC recurrence in a Chinese population (Xing et al., 2011). The SNPs rs4444235 (14q22.2), rs961253 (20p12.3), rs9929218, and rs10411210 were identified from a meta-analysis (Houlston et al., 2008). For the other SNPs, only associations with CRC have been recognized. Because of the shared molecular mechanism(s) in carcinogenesis and cancer progression, we hypothesized that these CRC genetic variants would be associated with the risk of GC. In the current study, we successfully assessed 10 SNPs in 249 GC cases and 292 controls. Mechanistically, rs6983267 was hypothesized to confer risk for colorectal cancer (Pomerantz et al., 2009) and prostate cancer (Wasserman et al., 2010) by influencing MYC expression; however, negative evidence has also been reported (Prokunina-Olsson and Hall; 2009). The SNP rs4444235 showed cis-acting regulation of bone morphogenetic protein 4 (BMP4) (Lubbe et al., 2012), although the relevant mechanisms remain unknown. For the 2 8q24 SNPs, rs6983267 and rs10505477, which were previously identified in solid tumorassociated polymorphisms, we only observed a significant association with GC risk in females. Two previous similar studies reported different results. The SNP rs6983267 was found to be associated with GC risk in another Chinese population (Guo et al., 2011), with the GT genotype having a higher risk than the GG genotype. In contrast, a Caucasian population-based study showed no significant association between rs6983267 or rs 10505477 and GC risk (Lochhead et al., 2011), reflecting a potentially population-specific effect. In addition, we found that rs16892766 was monomorphic with the AA genotype in our study group, which is consistent with HapMap data for the CHB and JPT populations, as well as with the results of a previous study (He et al., 2011) in Japanese Americans. These results indicate a possible monomorphy and unnecessary redundancy for further assessment of rs 16892766 in Asian populations.

In conclusion, this association study investigated 12 newly identified SNPs from CRC GWAS as genetic susceptibility factors for GC in a Chinese population. The present replication of genetic associations from CRC to GC highlights the utility of case-control follow-up studies to confirm novel associations characterized in large GWAS of digestive system dis- 
eases. Our study provides the first reported data of a possible association between the SNPs rs4444235 and rs10411210 and GC risk. These SNPs require further investigation before definitive conclusions can be drawn.

\section{ACKNOWLEDGMENTS}

Study supported by the Research Fund for the Doctoral Program of Higher Education of China (Grant \#20104433120016) and the National High Technology Research and Development Program of China (Grant \#2012AA020205). We would like to express our deepest gratitude to all the patients and healthy controls who participated in the study.

\section{Supplementary material}

\section{REFERENCES}

Abnet CC, Freedman ND, Hu N, Wang Z, et al. (2010). A shared susceptibility locus in PLCE1 at 10q23 for gastric adenocarcinoma and esophageal squamous cell carcinoma. Nat. Genet. 42: 764-767.

Beuten J, Gelfond JA, Martinez-Fierro ML, Weldon KS, et al. (2009). Association of chromosome 8q variants with prostate cancer risk in Caucasian and Hispanic men. Carcinogenesis 30: 1372-1379.

Crew KD and Neugut AI (2006). Epidemiology of gastric cancer. World J. Gastroenterol. 12: 354-362.

Crowther-Swanepoel D, Broderick P, Di Bernardo MC, Dobbins SE, et al. (2010). Common variants at 2q37.3, 8q24.21, $15 \mathrm{q} 21.3$ and 16q24.1 influence chronic lymphocytic leukemia risk. Nat. Genet. 42: 132-136.

Easton DF, Pooley KA, Dunning AM, Pharoah PD, et al. (2007). Genome-wide association study identifies novel breast cancer susceptibility loci. Nature 447: 1087-1093.

Enciso-Mora V, Broderick P, Ma Y, Jarrett RF, et al. (2010). A genome-wide association study of Hodgkin's lymphoma identifies new susceptibility loci at 2p16.1 (REL), 8q24.21 and 10p14 (GATA3). Nat. Genet. 42: 1126-1130.

Epplein M, Nomura AM, Hankin JH, Blaser MJ, et al. (2008). Association of Helicobacter pylori infection and diet on the risk of gastric cancer: a case-control study in Hawaii. Cancer Causes Control 19: 869-877.

Fletcher O, Johnson N, Gibson L, Coupland B, et al. (2008). Association of genetic variants at 8q24 with breast cancer risk. Cancer Epidemiol. Biomarkers Prev. 17: 702-705.

Fletcher O, Johnson N, Orr N, Hosking FJ, et al. (2011). Novel breast cancer susceptibility locus at 9q31.2: results of a genome-wide association study. J. Natl. Cancer Inst. 103: 425-435.

Ghoussaini M, Song H, Koessler T, Al Olama AA, et al. (2008). Multiple loci with different cancer specificities within the $8 \mathrm{q} 24$ gene desert. J. Natl. Cancer Inst. 100: 962-966.

González CA, Sala N and Capella G (2002). Genetic susceptibility and gastric cancer risk. Int. J. Cancer 100: 249-260.

Goode EL, Chenevix-Trench G, Song H, Ramus SJ, et al. (2010). A genome-wide association study identifies susceptibility loci for ovarian cancer at 2q31 and 8q24. Nat. Genet. 42: 874-879.

Guo Y, Fang J, Liu Y, Sheng HH, et al. (2011). Association between polymorphism rs6983267 and gastric cancer risk in Chinese population. World J. Gastroenterol. 17: 1759-1765.

He J, Wilkens LR, Stram DO, Kolonel LN, et al. (2011). Generalizability and epidemiologic characterization of eleven colorectal cancer GWAS hits in multiple populations. Cancer Epidemiol. Biomarkers Prev. 20: 70-81.

Houlston RS, Webb E, Broderick P, Pittman AM, et al. (2008). Meta-analysis of genome-wide association data identifies four new susceptibility loci for colorectal cancer. Nat. Genet. 40: 1426-1435.

Kiemeney LA, Thorlacius S, Sulem P, Geller F, et al. (2008). Sequence variant on 8q24 confers susceptibility to urinary bladder cancer. Nat. Genet. 40: 1307-1312.

Ladeiras-Lopes R, Pereira AK, Nogueira A, Pinheiro-Torres T, et al. (2008). Smoking and gastric cancer: systematic review and meta-analysis of cohort studies. Cancer Causes Control 19: 689-701.

Lascorz J, Forsti A, Chen B, Buch S, et al. (2010). Genome-wide association study for colorectal cancer identifies risk polymorphisms in German familial cases and implicates MAPK signalling pathways in disease susceptibility. Carcinogenesis 31: 1612-1619.

Li FX, Yang XX, He XQ, Hu NY, et al. (2012). Association of 10q23 with colorectal cancer in a Chinese population. Mol. Biol. Rep. 39: 9557-9562. 
Li X, Yang XX, Hu NY, Sun JZ, et al. (2011). A risk-associated single nucleotide polymorphism of SMAD7 is common to colorectal, gastric, and lung cancers in a Han Chinese population. Mol. Biol. Rep. 38: 5093-5097.

Lochhead P, Ng MT, Hold GL, Rabkin CS, et al. (2011). Possible association between a genetic polymorphism at 8q24 and risk of upper gastrointestinal cancer. Eur. J. Cancer Prev. 20: 54-57.

Lubbe SJ, Pittman AM, Olver B, Lloyd A, et al. (2012). The 14q22.2 colorectal cancer variant rs 4444235 shows cis-acting regulation of BMP4. Oncogene 31: 3777-3784.

Pomerantz MM, Ahmadiyeh N, Jia L, Herman P, et al. (2009). The 8q24 cancer risk variant rs6983267 shows long-range interaction with MYC in colorectal cancer. Nat. Genet. 41: 882-884.

Prokunina-Olsson L and Hall JL (2009). No effect of cancer-associated SNP rs6983267 in the 8q24 region on coexpression of MYC and TCF7L2 in normal colon tissue. Mol. Cancer 8: 96.

Rothman N, Garcia-Closas M, Chatterjee N, Malats N, et al. (2010). A multi-stage genome-wide association study of bladder cancer identifies multiple susceptibility loci. Nat. Genet. 42: 978-984.

Schumacher FR, Berndt SI, Siddiq A, Jacobs KB, et al. (2011). Genome-wide association study identifies new prostate cancer susceptibility loci. Hum. Mol. Genet. 20: 3867-3875.

Shete S, Hosking FJ, Robertson LB, Dobbins SE, et al. (2009). Genome-wide association study identifies five susceptibility loci for glioma. Nat. Genet. 41: 899-904.

Solé X, Guino E, Valls J, Iniesta R, et al. (2006). SNPStats: a web tool for the analysis of association studies. Bioinformatics 22: 1928-1929.

Takata R, Akamatsu S, Kubo M, Takahashi A, et al. (2010). Genome-wide association study identifies five new susceptibility loci for prostate cancer in the Japanese population. Nat. Genet. 42: 751-754.

Tan IB, Ng I, Tai WM and Tan P (2012). Understanding the genetic basis of gastric cancer: recent advances. Expert. Rev. Gastroenterol. Hepatol. 6: 335-341.

Tenesa A, Farrington SM, Prendergast JG, Porteous ME, et al. (2008). Genome-wide association scan identifies a colorectal cancer susceptibility locus on 11q23 and replicates risk loci at 8q24 and 18q21. Nat. Genet. 40: 631-637.

Tomlinson I, Webb E, Carvajal-Carmona L, Broderick P, et al. (2007). A genome-wide association scan of tag SNPs identifies a susceptibility variant for colorectal cancer at 8q24.21. Nat. Genet. 39: 984-988.

Tomlinson IP, Webb E, Carvajal-Carmona L, Broderick P, et al. (2008). A genome-wide association study identifies colorectal cancer susceptibility loci on chromosomes 10p14 and 8q23.3. Nat. Genet. 40: 623-630.

Turnbull C, Ahmed S, Morrison J, Pernet D, et al. (2010). Genome-wide association study identifies five new breast cancer susceptibility loci. Nat. Genet. 42: 504-507.

Wasserman NF, Aneas I and Nobrega MA (2010). An 8q24 gene desert variant associated with prostate cancer risk confers differential in vivo activity to a MYC enhancer. Genome Res. 20: 1191-1197.

White KL, Sellers TA, Fridley BL, Vierkant RA, et al. (2010). Variation at 8q24 and 9p24 and risk of epithelial ovarian cancer. Twin. Res. Hum. Genet. 13: 43-56.

Xing J, Myers RE, He X, Qu F, et al. (2011). GWAS-identified colorectal cancer susceptibility locus associates with disease prognosis. Eur. J. Cancer 47: 1699-1707.

Zanke BW, Greenwood CM, Rangrej J, Kustra R, et al. (2007). Genome-wide association scan identifies a colorectal cancer susceptibility locus on chromosome 8q24. Nat. Genet. 39: 989-994. 